\title{
Obituary: A Remembrance of Robert S. Siffert MD (1918-2015)
}

\author{
Jonathan J. Kaufman PhD
}

I first met Robert S. Siffert MD in 1982 at The Mount Sinai Medical Center in New York City. For the next 33 years, Dr. Siffert (Fig. 1) and I were alternately, and concurrently, mentor and protégé, colleagues, and dear friends. I miss him in all those ways, every day.

A few months prior to meeting Dr. Siffert, I had graduated from Columbia University with a doctorate in

The author certifies that he, or any member of his immediate family, has no funding or commercial associations (eg, consultancies, stock ownership, equity interest, patent/ licensing arrangements, etc.) that might pose a conflict of interest in connection with the submitted article.

All ICMJE Conflict of Interest Forms for authors and Clinical Orthopaedics and Related Research ${ }^{\mathbb{B}}$ editors and board members are on file with the publication and can be viewed on request.

The opinions expressed are those of the writers, and do not reflect the opinion or policy of $C O R R^{\circledR}$ or The Association of Bone and Joint Surgeons ${ }^{\mathbb{R}}$.

J. J. Kaufman PhD (ه)

CyberLogic Inc., 611 Broadway, Suite

707, New York, NY 10012, USA

e-mail: jjkaufman@cyberlogic.org

\section{J. J. Kaufman $\mathrm{PhD}$}

The Mount Sinai Medical Center, One Gustave L. Levy Place, New York, NY 10029, USA electrical engineering. I did not want to teach, nor did I want to design the next generation of cruise missiles (with my signal-processing background). It was by chance (or bashert- "fate" in Yiddish) that I happened to visit a friend whose lab had just moved from Columbia University Medical Center to Mount Sinai Orthopaedics (at Dr.
Siffert's invitation). My friend's lab was in the process of researching the use of electromagnetic fields for healing nonunions. I quickly joined this bioelectrochemistry lab. During that first year, Dr. Siffert-who I knew of, but had relatively little interaction with-arrived at my desk one day holding a series of radiographs of his

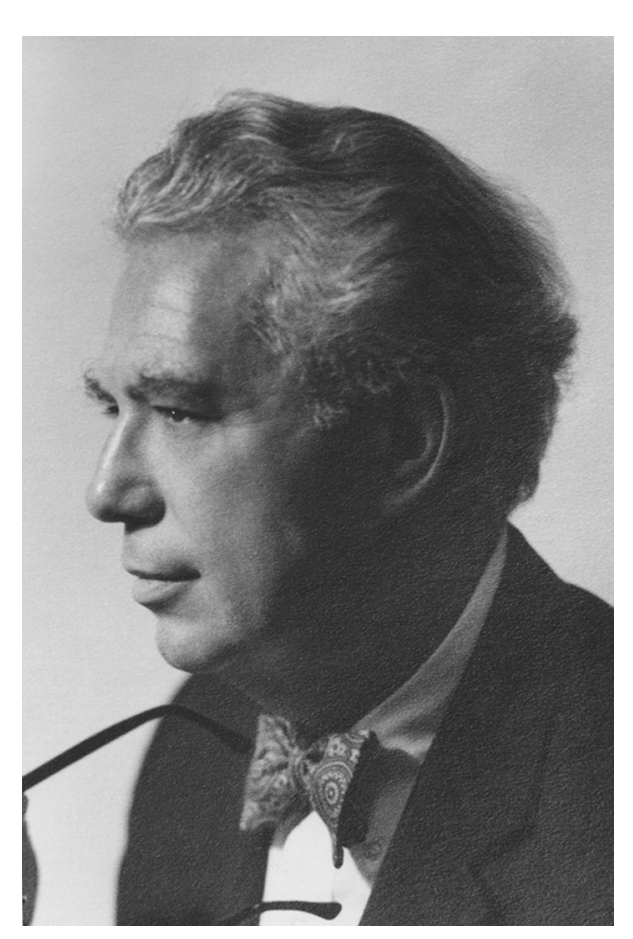

Fig. 1 In 1960, Dr. Siffert became the Director of the Department of Orthopaedics and Orthopaedic Surgeon-in-Chief at Mount Sinai Hospital in New York City. (Published with permission from The Mount Sinai Archives). 
patient's fractured distal fibula, which included the calcaneus. The radiographs showed the course of healing over several weeks. He asked me if it might be possible to quantify the temporal changes in calcaneal trabecular structure from disuse that he observed in the radiographs. Recognizing that this could be approached as a pattern-recognition problem, we employed methods of texture analysis that provided a quantitative measure of the trabecular structure changes. This early work on digital image processing of plain radiographs_-or as Dr. Siffert referred to it in his own prior published work from 1967 [1] as "analysis of summated patterns" _ provided insights into the structure and strength of bone. In fact, his analysis of radiographs as summated patterns provided a theoretical basis [2] for the recently developed Trabecular Bone Score, a new tool for assessing fracture risk in osteoporosis. And thus began our 33year relationship.

Dr. Siffert was born in Brooklyn, NY, USA in 1918. He attended James Madison High School in Brooklyn, where he met Miriam, his beloved high school sweetheart and wife of 67 years.

After graduating from New York University Medical School (Class of '43) — and having always been fascinated by aviation-Dr. Siffert entered the US Air Force. After about 4 months of training, he was assigned as a flight surgeon in the China-BurmaIndia Theater (known as The Hump). His mission was to attend to the flying personnel on flights into China, considered dangerous enemy territory at the time. For his brave efforts, Dr. Siffert was awarded four battle stars. While on a mission in India, Miriam gave birth to their daughter, Joan. Because of his US Air Force commitments, Dr. Siffert did not see his daughter until she was 6 months old.

Upon his return from the war, Dr. Siffert began his surgical residency at Mount Sinai Hospital in New York City in 1946. He also spent time in the lab, and began publishing seminal research papers [3, 4]. His career would blossom. In 1960, he became the Director of the Department of Orthopaedics and Orthopaedic Surgeon-in-Chief at Mount Sinai. With the formation of the Mount Sinai School of Medicine, he became the first (voluntary) Chairman of the Department of Orthopaedics in 1966. He served the position until 1986, and then as Acting Chairman in 1993.

Dr. Siffert (Fig. 2) received numerous awards during his illustrious career, including the Arthritis Foundation Lifetime Achievement Award, the Mount Sinai Hospital Jacobi Medallion, and the Richman Award for Humanism and Ethics.

For all of his accomplishments, one of his most treasured roles was as teacher to the more than 100 orthopaedists he trained as residents at Mount Sinai. This was entirely mutual: His residents adored him as well.

Another passion of Dr. Siffert's was helping children with orthopaedic disabilities. He established a children's orthopaedic clinic at Mount Sinai that permitted doctors from around the New York City area to refer patients for consultation and specialized care. His lay book, See How They Grow: A Parent's Guide to Normal and Abnormal Growth from Birth through Adolescence [5] is considered a tremendous guide for parents of children with orthopaedic disabilities. On top of his efforts with children, Dr. Siffert served for more than three decades on the board of CARE, a humanitarian organization that provides disaster relief and fights poverty around the world. He would spend month-long periods of time working with and training doctors in Indonesia, Afghanistan, Tunisia, and Haiti.

Dr. Siffert also had an extremely successful and active private practice for more than 50 years; his patients loved him. Many of his patients came from multiple generations within the same family. His devotion to his patients and identification of the best course of treatment is legendary. One patient who had been unable to find relief for his aching back found Dr. Siffert by a friend's recommendation. After seeing Dr. Siffert at 


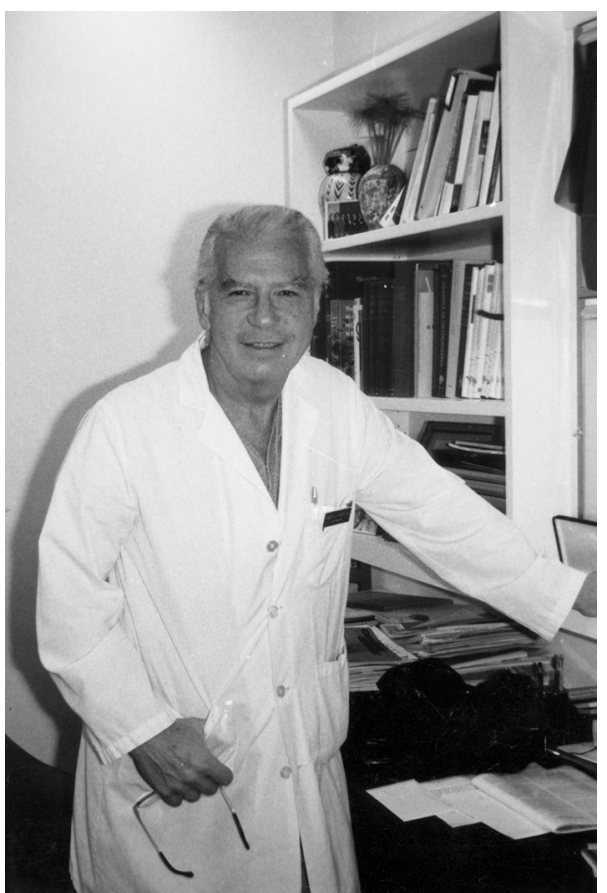

Fig. 2 Dr. Siffert received numerous awards during his illustrious career, including the Arthritis Foundation Lifetime Achievement Award, the Mount Sinai Hospital Jacobi Medallion, and the Richman Award for Humanism and Ethics. (Published with permission from The Mount Sinai Archives).

his office, the patient was so grateful for his pain-free back that he provided funding for Dr. Siffert's research at Mount Sinai for 20 years.

Outside of medicine, Dr. Siffert was a talented and prolific artist. Woodblock prints lined the hallways of his large practice (which he shared with his former residents-then partners Roger Levy MD and Herb Sherry MD). He loved the wood-block print process, the hand-carving of the block, and the printing on paper using multiple-colored inks. Dozens of his woodcuts now hang on permanent display at the Federal Courthouse in lower Manhattan [6]. He gave me one of his works several years ago on which he wrote: "To Jonathan ... My dear friend and colleague." An uninscribed copy of it is shown here (Fig. 3). It is one of my favorite pieces.
Dr. Siffert also loved the opera, classical music, history, and museums. He would very often hand me one of his membership cards, and say, "Go see some art." I think of him every time I take out my own membership card at a museum entrance. Ever the historian, Dr. Siffert set out to preserve the history of Orthopaedics at Mount Sinai from its humble beginnings. Remarkably, he constructed the Orthopaedic Archives, which included photos of the department's early chairmen (starting in 1909), orthopaedic tools such as the (Robert K.) Lippmann screw from 1936, as well as reprints and books by the hundreds of physicians and researchers affiliated with Sinai Orthopedics during the last 100 years. Much to Dr. Siffert's delight, these archives are now safely stored for posterity and research in the Levy Library at Mount Sinai [7].

After Dr. Siffert closed his practice (he insisted that he never retired, but "graduated" to continue his research in osteoporosis and his artwork), we continued our work in image analysis of bone structure, and expanded it to include adaptive bone remodeling, and ultrasonic assessment of bone. $\mathrm{He}$ would often take the subway down to my office for lunch. One week in the spring, we were sitting outside eating at a restaurant, and I asked if he would be willing to examine a friend who had injured his arm. He agreed, and as my 


\section{Obituary}

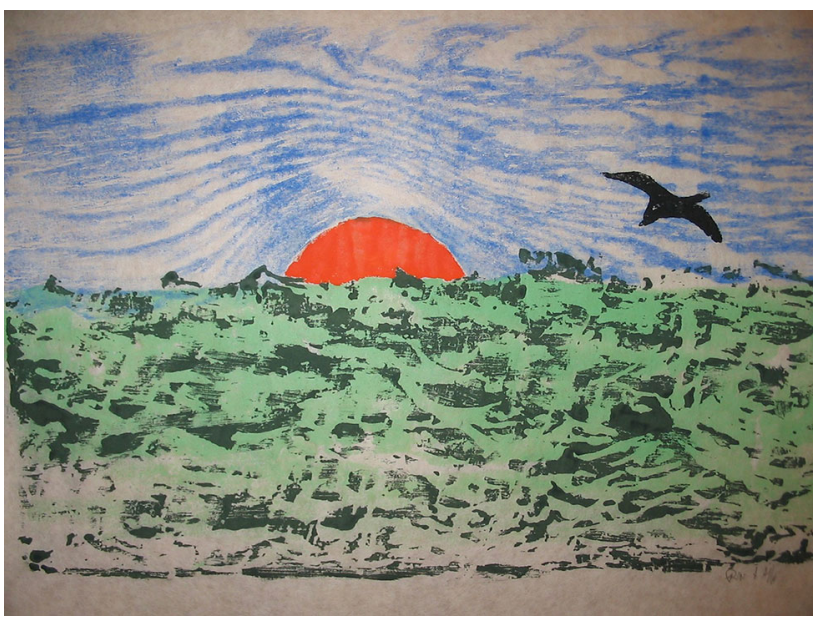

Fig. 3 An avid artist, a number of Dr. Siffert's woodcuts hang on permanent display at the United States Courthouse in Manhattan [6]. (Published with permission from Jonathan J. Kaufman PhD).

friend walked over to our table, Dr. Siffert said, "Here?" After the tableside outdoor examination, it was confirmed that my friend had a fractured olecranon.

During the last several years, I would visit Dr. Siffert every Tuesday at his home. We would talk about everything before, during, and after lunch. (Lox on a toasted bagel with cream cheese, followed by tea, of course). We would discuss work, but we would talk about life and our families, too. He loved his family, and he would always marvel at how he got to be so lucky. His daughter Joan and son John (who has two sons Matthew and David, while I have two brothers Matthew and David) would joke that I was the "good son."

His kindness was a blessing to me. Two months before he died, he phoned to ask whether I could come to his home-he said his printer was not working. When I arrived, I looked at the printer-but could not find anything wrong with it. He confided, "I just wanted to see you." I am lucky to have arrived at Mount Sinai in 1982 and grateful for meeting this wonderful, exceptional man.

\section{References}

1. Siffert RS. Trabecular patterns in bone. Am. J. Roentgenol. 1967;99: 746-755.

2. Luo GM, Kinney JH, Kaufman JJ, Haupt D, Chiabrera A, Siffert RS. Osteoporosis Int. 1999;9:339-345.

3. Siffert RS. The demonstration of $\mathrm{p} 32$ in bone by radioautography. Science. 1948;108:445-448.

4. Siffert RS. The role of alkaline phosphatase in osteogenesis. J Exp Med. 1951;93:415-426.

5. Siffert RS. See How They Grow: A Parent's Guide to Normal and Abnormal Growth from Birth through Adolescence. Baltimore, MD: Raven Press; 1985.

6. Barron J. A different kind of courthouse artist. Available at: http://city room.blogs.nytimes.com/2009/06/11/ a-different-kind-of-courthouse-artist/? $\mathrm{r}=0$. Accessed February 18, 2016.

7. Icahn School of Medicine at Mount Sinai. Mount Sinai archives collections. Available at: http://library.mssm. edu/services/archives/archives_collec tions/orthopaedics.shtml. Accessed February 18, 2016. 